\title{
Endocannabinoid Stimulated Release of Nitric Oxide and its Mitochondrial Influence Triggering Vascular Pathology
}

\author{
George B Stefano*, Erin Quinn and Richard M Kream
}

MitoGenetics LLC, 3 Bioscience Park Drive, Suite 307, Farmingdale, NY 11735, USA

\begin{abstract}
Endocannabinoids, and their respective receptors, are involved in a host of cellular regulatory activities. In part, some of these mediated effects occur by way of stimulating constitutive nitric oxide release. This occurs in endothelia, certain white blood cells, microglia, and in similar invertebrate tissues, demonstrating that this is a conserved chemical messenger system. This endocannabinoid chemical messenger system, coupled to constitutive nitric oxide release, also appears to exert regulatory effects on mitochondrial energy associated processes, further substantiating its primordial history. In this regard, it appears to offer some beneficial actions in the occurrence of reperfusion injury and stroke. The mechanism envisioned is one initiated via a hypoxic event, which does not restore normalcy, then progresses to a pro-inflammatory state, and the resultant chronic condition manifests itself in a specific disorder. This fits nicely into a vascular-associated origin for Alzheimer's Disease, whereby the proinflammatory state encompasses vessels that have endothelial gaps, providing for a compromised blood brain barrier, beta amyloid deposition, and enhanced white blood cell trafficking. In time, due to the physical progression of the events, Alzheimer's Disease occurs.
\end{abstract}

Keywords: Marijuana; Anandamide; Mitochondria; Vascular; Alzheimer's disease; Nitric oxide

\section{Constitutive Nitric Oxide (NO)}

Constitutive nitric oxide synthase (cNOS) is responsible for both tonic and phasic production of nitric oxide $(\mathrm{NO})$ which is released via physiological stimuli [1]. The enhanced cNOS-mediated release of NO can exert profound physiological actions, well after NO returns to its tonal level [2]. For example, endothelial cells exposed to an appropriate chemical messenger may take hours to change conformation [2], demonstrating that these enhanced NO levels are physiologically important.

Inhibitory NOS is also induced by various signal molecules, e.g., pro-inflammatory cytokines [3-5], after a 3-4 h delay and its release remains high for 24-48 hours [4,5]. Therefore, inducible NOS (iNOS) $\mathrm{NO}$ is in the environment for a much longer period of time, suggesting that $\mathrm{NO}$ is always present and that its levels can change quickly for a short period of time, or induced, so that it is present at high concentrations, for a longer time. These different processes imply either a different function of $\mathrm{NO}$, or a role that requires $\mathrm{NO}$ to be progressively increased to exert its action, or a combination of the two. We surmise that this low level of NO (nM range) provides an organism with a major pathway that functions to dampen micro-environmental "noise" which would otherwise nonspecifically and inappropriately activate immune, endothelial and neural cells [6]. NO may control the threshold for activation of these cells. For example, when excitatory signals, i.e., lipopolysaccharide, are present at detectable levels, the tonal inhibition due to NO is overcome and activation occurs. Thus, the activation mechanism really represents a disinhibition process [6]. Activation, representing the overcoming of the NO inhibitory influence, occurs by tipping the balance between tonal $\mathrm{NO}$ and the levels of excitatory signal molecules, since these also may be constitutively expressed. Taken together, the disinhibition phenomenon suggests that these cells are always "on". This, in itself, represents an important survival strategy, since these cells are constantly ready to protect their respective systems, requiring only one step for activation, that is, disinhibition.

\section{Tonal Nitric Oxide}

We have measured a baseline level of NO, using an amperometric probe, in endothelial cells, monocytes, granulocytes and invertebrate ganglia and immunocytes [2]. Based on this observation, it is safe to conclude that NO may be produced in these tissues at very low levels. Based on the information presented in the earlier sections of this review, we believe that this tonal NO is physiologically significant. We speculate that tonal NO tends to diminish the natural excitatory nature of these cells, and in so doing, it provides for a threshold level of stimulation that needs to be overcome. Once a threshold level of stimulation occurs, it simply "tips" the balance of signal molecule strength in favor of excitation. In other words, excitation occurs by disinhibition.

In blood vessels, i.e., endothelia, obtained from patients during coronary artery bypass surgery, non-insulin dependent diabetics do not exhibit a tonal level of NO [7]. Generally, in patients with noninsulin-dependent diabetes mellitus, vascular disease causes disability and death [8]. A number of authors, including us, have attributed vascular disease, in part, to alterations associated with endotheliumderived NO. Some have speculated this also may be due to enhanced free radical generation [9]. Indeed, decreases in the basal level of NO may also contribute to enhanced platelet function, as well as neuropathies $[10,11]$. Taken together, it would appear that tonal NO is quite important in limiting the degree of excitation of nervous, immune and vascular tissues. Furthermore, this tonal NO may manifest itself via effects on the local expression of adhesion via NF- $\mathrm{KB}$-mediated processes. Clearly, other cascading mechanisms may also be involved [12]. In all likelihood, estrogen may exert its beneficial vascular protective actions via these processes as well, since it also releases cNOS derived endothelial NO $[13,14]$.

*Corresponding author: George B Stefano, MitoGenetics LLC, 3 Bioscience Park Drive, Suite 307, Farmingdale, NY 11735, USA, Tel: 631-227-3930; E-mail: George.Stefano@MitoGenetics.com

Received April 30, 2015; Accepted May 28, 2015; Published June 04, 2015

Citation: Stefano GB, Quinn E, Kream RM (2015) Endocannabinoid Stimulated Release of Nitric Oxide and its Mitochondrial Influence Triggering Vascular Pathology. Pharm Anal Acta 6: 378. doi:10.4172/21532435.1000378

Copyright: (c) 2015 Stefano GB, et al. This is an open-access article distributed under the terms of the Creative Commons Attribution License, which permits unrestricted use, distribution, and reproduction in any medium, provided the original author and source are credited. 


\section{Cell Shape}

NO stimulated cell conformational changes extend to human monocytes and granulocytes, human endothelial cells and invertebrate immunocytes and microglia [2,15-21].Various endogenous signaling molecules, whose receptors are coupled to cNOS, can bring about the relatively rapid change of shape. For example, both anandamide, an endogenous endocannabinoid, and morphine exhibit this ability in human and invertebrate immunocytes, microglia and human endothelial cells $[2,16,18,22]$. Furthermore, once the cNOS derived NO down regulating activity (causing cells to be round and inactive) wears off, the cells, for a short period of time, exhibit a simple rebound effect characterized by hyperactivity [21]. This suggests, that NO, in a counter-intuitive process, can also activate cells. Cell activation, as noted by cell shape changes, has been reported by Goligorsky and colleagues for endothelial cells after a prolonged incubation period [23-25].

Besides the intercellular influence of $\mathrm{NO}$ on cell shape changes, $\mathrm{NO}$ has been shown to act within the cell to initiate regional shape changes, i.e., to cause cells to extend or retract portions of their cytoplasm [2325]. We can speculate that these intracellular effects on cell shape may be the basis for cellular communication within the median eminence and provide a mechanism for exocytosis into capillary beds $[13,26]$.

\section{Molecular Mechanisms}

NO inhibits endothelial cell-leukocyte activation [27-29]. The mechanism of NO action appears to be at the level of adhesion molecules. Sodium nitroprusside, a potent NO donor, inhibits the adhesion of gel-filtrated thrombin stimulated platelets and leukocytes, which is mediated by selectin-P [30]. The beta 2-integrin CD18 and the endothelial cell adhesion molecule ICAM-1 increase the surface adhesion of neutrophils to endothelial cells; this increased adhesion can be blocked by exposure to the NO-donor, N-nitro-Larginine methyl ester (L-NAME), or to monoclonal antibodies directed against these molecules [31] NO donors also decreased polymorphonuclear leukocyte interactions in the microvasculature of post-ischemic tissue [32]. In this study, rolling and firm adhesion (adherence) of leukocytes and shear rate were monitored in cat mesenteric venules. The study suggested that NO donors may provide protection from tissue injury by preventing immunocyte adhesion. Our previous reports also support this hypothesis [17,18,33-38].

DeCaterina and colleagues [39] found that exposing IL-1 $\alpha$ stimulated human saphenous vein endothelial cells to NO donors resulted in a concentration-dependent inhibition of VCAM-1 expression and reduced monocyte adhesion to endothelial monolayers. The same phenomenon was observed after stimulation by IL$1 \alpha$, IL-1 $\beta$, IL-4, tumor necrosis factor (TNF alpha), or bacterial lipopolysaccharide (LPS) [39]. Furthermore, NO also decreased the endothelial expression of E-selectin and secretable IL-6 and IL-8. NO probably represses VCAM-1 gene transcription by inhibiting NFkappa B [39]. These authors propose that the effect of NO on cytokine synthesis may contribute, in part, to its anti-atherogenic and antiinflammatory properties. From this study alone, one may conclude that NO can have potent and widespread anti-inflammatory actions.

\section{Cannabinoids}

In a study, our group demonstrated stereo-selective binding sites for anandamide in invertebrate immunocytes and microglia [20,40]. This binding site is coupled to NO release, both in invertebrate tissues and in human monocytes. Interestingly, the cannabinoid stimulated release of NO initiates cell rounding and resembles those of opiate alkaloids. These signaling systems utilize the same effector system, i.e., NO release, but by separate receptors $[20,40]$. Additionally, anandamide signaling has been demonstrated in rat blood vessels where it can also cause vasodilation [43]. In this report, $\mathrm{CB} 1$, an endocannabinoid receptor, receptor material and anandamide were also found, indicating that this signaling may involve autovascular regulation as well.

Tetrahydrocannabinol (THC) inhibits macrophage cell contactdependent cytolysis of tumor cells [42]. THC also appears to alter antigen processing [43] and the expression of select proteins whose induction is associated with macrophage activation, as well as the expression of TNF $[44,45]$. THC was found to increase the bioactivity of IL-1 in cultures of mouse resident LPS-stimulated peritoneal macrophages [46]. Incubating P388D1 macrophage cell cultures with THC results in a dose-dependent inhibition of cell propagation, DNA synthesis and phagocytosis [47]. In earlier reports, THC was found to inhibit human peripheral blood macrophage spreading and phagocytosis [48-51].

The inhibition of cell spreading $[48,49]$ is in agreement with observations made by Stefano, which demonstrate [20,22] that anandamide receptor coupling to NO may be the mechanism initiating this cell rounding $[2,16]$. Thus, naturally occurring cannabinoids and opiate alkaloids may utilize the same NO-producing effector system.

Specifically, anandamide effector processes are coupled to NO release in human endothelial cells $[5,8,20]$. We demonstrated that cNOS derived NO release regulated iNOS activity and concluded that endogenous signaling molecules may use NO to directly inhibit adenylate cyclase activity [5]. Our results also demonstrate that cNOS derived NO regulates iNOS expression [5].

\section{Clinical Observations on THC, Mitochondria and Vascular Tissues}

In light of the molecular and cellular studies cited, on a clinical level there are vulnerabilities to addiction associated with cannabis. Simultaneously, it has been shown to have great beneficial value with several diseases [52]. Cancer, pain, neurodegenerative disorders, Alzheimer's Disease and psychiatric disorders are some of the diseases that have been or have the potential to be treated with cannabinoids. THC, the psychoactive component of cannabis, produces a countless amount of pharmacological effects in animals and humans [53]. THC exhibits serious negative outcomes, as well [54]. In regard to mitochondrial actions, tests on isolated rat brain mitochondria showed mitochondrial dysfunction, as well as oxidative stress [54]. Importantly, heightened hydrogen peroxide $\left(\mathrm{H}_{2} \mathrm{O}_{2}\right)$ production also was found. This observation is supported by others [55]. THC may induce multifocal intracranial arterial vasoconstriction [55], which may damage neurons via induced hypoxia [56]. Since these processes are major occurrences during stroke, the indication that THC may provoke an individual's susceptibility to it via creating circulatory pathologies, appears novel.

Validating the earlier empirical studies just noted, are the works by Aliev $(2014,2013)$, which also note vascular lesions and mitochondrial dysfunction, as components of the pathogenesis of Alzheimer's Disease [57,58]. A key component of their hypothesis is the involvement of NO as a contributing factor via mitochondrial targeting [59]. Nakamura and colleagues make an additional contribution to this pathogenesis by involving mitochondrial dysfunction in neurons and their processes, induced by abnormal protein folding presumably caused by high NO levels, suggesting iNOS stimulation [60]. Furthermore, Khan 
and colleagues (2012) again stress the significance of mitochondrial dysfunction and oxidative stress as causative factors in Alzheimer's Disease, which can be alleviated, to a degree, by thymoquinone [61]. Even in a rodent model, as noted earlier, blood flow appears to be a factor in Alzheimer's Disease initiation, involving the above cellular processes [62].

Sustained use of marijuana has suggested an association with problems such as cognitive dysfunction, cardiovascular disorders and restricted blood flow causing cerebral abnormalities [63]. Testing on serum protein levels proved that marijuana does, in fact, increase levels of apoliproprotein (apo) C-III, a cardiovascular risk factor, putting patients at risk for the above-mentioned complications. In part, this may also explain the association of THC with negative vascular outcomes [64,65]. Additionally, chronic bronchitis is associated with THC use, and in this process, it damages mitochondrial function and cellular energetics. THC appears to induce the uncoupling of electron transport [65]. Interestingly, this mitochondrial dysfunction lasts for hours, suggesting profound actions of this compound. In this regard, in culture, we have demonstrated that vascular endothelial cells can undergo prolonged cell shape changes lasting for hours after a short exposure to anandamide, suggesting many cannabis actions are not immediate [2].

Consistent marijuana smokers have shown a good amount of irregularities in lung function [66]. THC exposure caused mitochondrial injury in epithelial lung cells and in the cell line, A549. In conclusion, it was found that both CB2R-dependent and independent properties facilitated by THC altered the airway epithelial cells. Human lung cancer cells, viewed over time, showed that three different types of cannabinoids: anandamide, THC and HU210, all caused alterations that were typical of cell death, e.g., apoptosis [67]. This also reduced oxygen intake within rat heart mitochondria. Therefore, without cannabinoid receptors, these three ligands all produce a change in mitochondrial function. Important cellular functions, such as energy regulation and removal of unneeded cells, are changed by the endocannabinoid anandamide in mitochondria-dependent signal transduction [68]. Results showed mitochondrial swelling and reductions of calcium sensitivity following anandamide exposure, which suggests that the anandamide changes the physiology of mitochondria.

Additionally, cannabinoids appear to be important mediators in the pathophysiology of inflammatory diseases, such as atherosclerosis [69]. They also lessen the ischemic injury after acute cardiovascular events. The properties of cannabinoids are characteristically attributed to the activation of the two major cannabinoid receptors, $\mathrm{CB} 1$ and CB2. CB1 receptor stimulation has been revealed to directly diminish atherosclerotic plaque inflammation while $\mathrm{CB} 2$ produces protective effects against acute post stroke inflammation. In this regard, we've demonstrated that both receptors can be coupled to cNOS stimulated NO release in human endothelia cells $[20,27,38,41]$. These reports demonstrate the intimate association of cannabinoid signaling and vascular regulation.

Oxygen consumption and oxidative phosphorylation constitutes the energy process needed for sodium chloride $(\mathrm{NaCl})$ reabsorption in the thick ascending limb the loop of Henle [70] Through the activation of cannabinoid receptors $\mathrm{CB}-1$ and $-2, \mathrm{Na}$ transport in other cells is suppressed by anandamide. Since NO hinders transport and the CB1 receptors are associated with NOS, the role of NO was assessed. The results of these tests indicated that anandamide does, in fact, hinder $\mathrm{Na}$ transport via its associated oxygen consumption through the stimulation of CB1 receptors and NOS. These findings indicate that the cannabinoids can directly lessen oxidative metabolism of tissue in isolated mitochondria [71]. Indeed, over the short term this may be the basis for endocannabinoids' reported beneficial actions, e.g., in stroke, decreasing energy processes in trauma to lessen a reactive oxygen species (ROS) presence.

Furthermore, detailed epidemiological, biochemical and physiological studies have demonstrated that rheumatoid arthritis, osteoarthritis, atherosclerosis, diabetes type 2, and Alzheimer's Disease, to name a few, are strongly associated with cardiovascular diseases in the general population, thereby establishing a clear functional connection between metabolic rundown encountered in Type II diabetics and the etiology of these disorders [72-86]. Their interrelationship also manifests itself in the phenomenon of co-morbidities [82,86,87]. Importantly, in these and other disorders, the central involvement of the vasculature is of singular significance because it supplies oxygen to the various tissues whose mitochondria require it instantaneously $[77,88,89]$.

\section{Conclusion}

In attempting to summarize this information, an Alzheimer's Disease hypothesis would be in order. In this scenario a minor event may occur in a "brain" blood vessel (e.g., lipid, ROS, trauma, etc.) initiating a micro environmental hypoxic state, which would alter mitochondrial activity. In this vascular hypothesis [77,90], under normal circumstances this event would be corrected, however, occurring in an abnormal micro-environment, it would progress in outcome. The induced hypoxia state would alter mitochondrial processes, which depend on an immediate oxygen supply, and cause it to revert to another energy pathway favoring aerobic glycolysis, producing less ATP $[89,90]$ initiating a chronic proinflammatory state [92]. This mitochondrial induced phenomenon would alter endothelial cell shape, since endothelial NO production would also be compromised, causing gaps in the vascular lining [75,88]. These gaps would allow immune cells to move in and out of the brain in greater numbers and cause the production of signaling molecules that are immune-stimulatory in nature. It would also allow for the continued build-up of beta amyloid-, tau -proteins and other molecules that are regarded as the hallmark of Alzheimer's disease. As this process continues, it spreads due to the proximity of hypoxic environments and compromised blood flow, increasing its frequency of presence over normal age-matched brains. In this regard, hypo-perfusion of the brain and a lack of NO, both influencers of mitochondrial regulation, do induce an Alzheimer's Disease-like vasculature [94,95]. Furthermore, the various co-morbidities associated with Alzheimer's Disease bring into consideration the many phenomena that suggest dysfunctional mitochondria are present.

The presence of a cannabinoid chemical messenger system, liberating NO from endothelial cells, brings into question an early cannabinoid involvement/failure, given its dependence on fatty acid mitochondrial driven metabolism. Again, its association with this disorder is also documented. Diverse signaling compounds use cNOS, thus amplifying tonal NO levels. Given the subtle nature of tonal NO's presence, we surmise that, in its absence, it would be hard to document its significance over the short term. However, over the long term we already may be observing its effects in progressively debilitating conditions such as diabetes type 2 [96]. In other chronic conditions involving inflammatory events, such as AIDS-associated neuropathies, we may also be observing conditions when tonal $\mathrm{NO}$ influences cannot be felt over the long term, leading to enhanced tissue damage and brain penetration. In this regard, we feel the current review opens up another 
area in NO research, long-term tonal NO release and its biomedical significance, and the potential involvement of endocannabinoids, as local chemical messengers, that may be among the first intercellular communication systems to fail, probably at the mitochondrial level.

\section{References}

1. Moncada S, Palmer RM, Higgs EA (1988) The discovery of nitric oxide as the endogenous nitrovasodilator. Hypertension 12: 365-372.

2. Magazine HI, Liu Y, Bilfinger TV, Fricchione GL, Stefano GB, et al. (1996) Morphine-induced conformational changes in human monocytes, granulocytes, and endothelial cells and in invertebrate immunocytes and microglia are mediated by nitric oxide. J. Immunol 156: 4845-4850.

3. Moncada S, Palmer RMJ, Higgs EA (1991) Nitric oxide: physiology, pathophysiology, and pharmacology. Pharmacological Reviews. 43: 109-142.

4. Radomski MW, Palmer RMJ, Moncada S (1990) Glucocorticoids inhibit the expression of an inducible, but not the consitutive, nitric oxide synthase in vascular endothelial cells. Proc. Natl. Acad. Sci. ,USA. 87:10043-10047.

5. Stefano GB, Salzet M, Magazine HI, Bilfinger TV (1998a) Antagonist of LPS and IFN-g induction of iNOS in human saphenous vein endothelium by morphine and anandamide by nitric oxide inhibition of adenylate cyclase. J Cardiovasc Pharmacol 31: $813-820$.

6. Stefano GB, Goumon Y, Bilfinger TV, Welters I, Cadet P, et al. (2000a) Basal nitric oxide limits immune, nervous and cardiovascular excitation: Human endothelia express a mu opiate receptor. Progress in Neurobiology 60: 513-530.

7. Bilfinger TV ( 1999) Role of morphine in blood pressure modulation: influence of nitric oxide. Acta Pharmacol Sinica. 20: 258-259.

8. Catalano MG, Carzaniga E, Perilli T, Jun G, Scandale S, et al.(1997) Basa nitric oxide production is not reduced in patients with noninsulin-dependent diabetes mellitus. Vascular Medicine. 2: 302-305

9. Nitenberg AS, Ledoux JR, Attali, Valensi P (1997) Response of the coronary arteries to cold test and flow velocity increase is improved by deferoxamine but not by L-arginine in diabetic patients. French Archives des Maladies du Coeur et des Vaisseaux 90: 1037-1041.

10. Huszka M, Kaplar M, Rejto L, Tornai I, Palatka K, et al. (1997) The association of reduced endothelium derived relaxing factor-NO production with endothelia damage and increased in vivo platelet activation in patients with diabetes mellitus. Thrombosis Research. 86: 173-180.

11. Pitei DL, Watkins PJ, Edmonds ME (1997) NO-dependent smooth muscle vasodilatation is reduced in NIDDM patients with peripheral sensory neuropathy. Diabetic Medicine. 14: 284-290.

12. Fimiani C, Liberty T, Aquirre AJ, Amin I, Ali N, et al. (1999) Opiate, cannabinoid and eicosanoid signaling converges on common intracellular pathways: nitric oxide coupling. Prostaglandins. 57: 23-34

13. Prevot V, Croix D, Rialas CM, Puolain P, Fricchione GL, et al. (1999) Estradio coupling to endothelial nitric oxide production stimulates $\mathrm{GnRH}$ release from rat median eminence. Endocrinol. 140: 652-659.

14. Stefano GB, Prevot V, Beauvillain JC, Bilfinger TV, Fimiani C, et al. (2000b ) Acute exposure of estrogen to human endothelia results in nitric oxide release mediated by an estrogen surface receptor coupled to intracellular calcium transients. Circulation. 101:1594-1597.

15. Liu Y, Shenouda D, Bilfinger TV, Stefano ML, Magazine HI, et al. (1996) Morphine stimulates nitric oxide release from invertebrate microglia. Brain Res. 722: 125-131.

16. Ottaviani E, Paemen LR, Cadet P, Stefano GB (1993). Evidence for nitric oxide production and utilization as a bacteriocidal agent by invertebrate immunocytes. Eur. J. Pharmacol. 248: 319-324.

17. Sonetti D, Ottaviani E, Bianchi F, Rodriquez M, Stefano ML,1994. Microglia in invertebrate ganglia. Proc. Natl. Acad. Sci. USA. 91:9180-9184.

18. Stefano GB, Hartman A, Bilfinger TV, Magazine HI, Liu Y, et al. (1995) Presence of the mu3 opiate receptor in endothelial cells. Coupling to nitric oxide production and vasodilation. J. Biol. Chem. 270: 30290-30293.

19. Stefano GB, Kim E, Liu Y, Zhu W, Casares F, et al. (2004) Nitric oxide modulates microglial activation. Med. Sci. Monit. 10: BR17-BR22.

20. Stefano GB, Liu Y, Goligorsky MS (1996) Cannabinoid receptors are coupled to nitric oxide release in invertebrate immunocytes, microglia, and human monocytes. J Biol Chem 271: 19238-19242.

21. Stefano GB, Salzet M, Rialas CM, Mattocks D, Fimiani C, et al. (1998) Macrophage behavior associated with acute and chronic exposure to HIV GP120, morphine and anandamide: endothelial implications. Int J Cardiol 64 Suppl 1: S3-13.

22. Stefano GB, Scharrer B, Smith EM, Hughes TK Jr, Magazine HI, et al. (1996) Opioid and opiate immunoregulatory processes. Crit Rev Immunol 16: 109-144.

23. Noiri E, Hu Y, Bahou WF, Keese CR, Giaever I, et al. (1997) Permissive role of nitric oxide in endothelin-induced migration of endothelial cells. J. Biol. Chem. 272: $1747-1752$

24. Noiri E, Lee E, Testa J, Quigley J, Colflesh D, et al. (1998) Podokinesis in endothelial cell migration: role of nitric oxide. Am J Physiol 274: C236-244.

25. Noiri E, Peresleni T, Srivastava N, Weber P, Bahou WF, et al. (1996) Nitric oxide is necessary for a switch from stationary to locomoting phenotype in epithelial cells. Am J Physiol 270: C794-802

26. Prevot V, Rialas CM, Croix D, Salzet M, Dupouy JP, et al. (1998) Morphine and anandamide coupling to nitric oxide stimulates GnRH and CRF release from rat median eminence: neurovascular regulation. Brain Res 790: 236-244.

27. Bilfinger TV, Salzet M, Fimiani C, Deutsch DG, Tramu G, et al. (1998) Pharmacological evidence for anandamide amidase in human cardiac and vascular tissues. Int J Cardiol 64 Suppl 1: S15-22.

28. Prevot V, Rialas CM, Croix D, Salzet M, Dupouy JP, et al. (1998) Morphine and anandamide coupling to nitric oxide stimulates $\mathrm{GnRH}$ and $\mathrm{CRF}$ release from rat median eminence: neurovascular regulation. Brain Res 790: 236-244.

29. Stefano GB (1998) Autoimmunovascular regulation: morphine and anandamide and ancondamide stimulated nitric oxide release. J Neuroimmunol 83: 70-76.

30. DembiÅ ska-KieÄ A, Zmuda A, Wenhrynowicz O, Stachura J, Peskar BA, et al. (1993) Selectin-P-mediated adherence of platelets to neutrophils is regulated by prostanoids and nitric oxide. Int J Tissue React 15: 55-64.

31. Niu XF, Smith CW, Kubes P (1994) Intracellular oxidative stress induced by nitric oxide synthesis inhibition increases endothelial cell adhesion to neutrophils. Circ Res 74: 1133-1140.

32. Kubes P, Kurose I, Granger DN (1994) NO donors prevent integrin-induced leukocyte adhesion but not P-selectin-dependent rolling in postischemic venules. Am J Physiol 267: H931-937.

33. Bilfinger TV, Fricchione GL, Stefano GB (1993) Neuroimmune implications of cardiopulmonary bypass. Adv. Neuroimmunol 3:277-288

34. Bilfinger TV, Hartman AR, Liu Y, Magazine HI, Stefano GB (1997) Cryopreserved veins in myocardial revascularization: possible mechanism for their increased failure. Ann Thorac Surg 63: 1063-1069.

35. Bilfinger TV, Kushnerik V, Bundz S, Liu Y, Stefano GB (1996) Evidence for morphine downregulating immunocytes during cardiopulmonary bypass in a porcine model. Int J Cardiol 53 Suppl: S39-46.

36. Bilfinger TV, Stefano GB (1996) Cellular aspects of cardiopulmonary bypass surgery. Int J Cardiol 53S: R7.

37. Liu Y, Shenouda D, Bilfinger TV, Stefano ML, Magazine HI, et al. (1996) Morphine stimulates nitric oxide release from invertebrate microglia. Brain Res 722: 125-131.

38. Bilfinger TV, Salzet M, Fimiani C, Deutsch DG, Tramu G, et al. (1998) Pharmacological evidence for anandamide amidase in human cardiac and vascular tissues. Int J Cardiol 64 Suppl 1: S15-22.

39. DeCaterina R, Libby P, Peng HB, Thannickal VJ, Rajavashisth TB, et al. (1995) Nitric oxide decreases cytokine-induced endothelial activation. Nitric oxide selectively reduces endothelial expression of adhesion molecules and proinflammatory cytokines. J Clin Invest 96: 60-81.

40. Stefano GB, Salzet M (1996) Characterization and coupling of the leech CNS cannabinoid receptor to nitric oxide release. J Biol Chem

41. Deutsch DG, Goligorsky MS, Schmid PC, Krebsbach RJ, Schmid HH, et al. (1997) Production and physiological actions of anandamide in the vasculature of the rat kidney. J Clin Invest 100: 1538-1546.

42. Burnette-Curley D, Cabral GA (1995) Differential inhibition of RAW264.7 macrophage tumoricidal activity by delta 9tetrahydrocannabinol. Proc Soc Exp Biol Med 210: 64-76. 
Citation: Stefano GB, Quinn E, Kream RM (2015) Endocannabinoid Stimulated Release of Nitric Oxide and its Mitochondrial Influence Triggering Vascular Pathology. Pharm Anal Acta 6: 378. doi:10.4172/21532435.1000378

43. McCoy KL, Gainey D, Cabral GA (1995) delta 9-Tetrahydrocannabinol modulates antigen processing by macrophages. J Pharmacol Exp Ther 273 1216-1223.

44. Cabral GA, Fischer-Stenger K (1994) Inhibition of macrophage inducible protein expression by delta-9-tetrahydrocannabinol. Life Sci 54: 1831-1844.

45. Zheng ZM, Specter S, Friedman H (1992) Inhibition by delta-9tetrahydrocannabinol of tumor necrosis factor alpha production by mouse and human macrophages. Int J Immunopharmacol 14: 1445-1452.

46. Shivers SC, Newton C, Friedman H, Klein TW (1994) delta 9-Tetrahydrocannabinol (THC) modulates IL-1 bioactivity in human monocyte/ macrophage cell lines. Life Sci 54: 1281-1289.

47. Tang JL, Lancz G, Spector S, Bullock H (1992) Marijuana and immunity: tetrahydrocannabinol-mediated inhibition of growth and phagocytic acitivity of the murine macrophage cell line, P388D1. Int J Immunopharmacol 14: 253 262

48. Friedman M, Cepero ML, Klein T, Friedman H (1986) Suppressive effect of delta 9-tetrahydrocannabinol in vitro on phagocytosis by murine macrophages. Proc Soc Exp Biol Med 182: 225-228.

49. Specter S, Lancz G, Goodfellow D (1991) Suppression of human macrophage function in vitro by delta 9-tetrahydrocannabinol. J Leukoc Biol 50: 423-426.

50. Specter S, Lancz G, Westrich G, Friedman H (1991b) Combined immunosuppressive activities of delta9- tetrahydrocannabinol and murine retrovirus. In Advances in experimental medicine and biology. Drugs of Abuse, Immunity, and Immunodeficiency Advances in Experimental Medicine and Biology 135-141

51. Specter S, Lancz G, Westrich G, Friedman H (1991) Delta-9 tetrahydrocannabinol augments murine retroviral induced immunosuppression and infection. Int J Immunopharmacol 13: 411-417.

52. Kogan NM, Mechoulam R (2007) Cannabinoids in health and disease. Dialogues Clin Neurosci 9: 413-430.

53. Adams IB, Martin BR (1996) Cannabis: pharmacology and toxicology in animals and humans. Addiction 91: 1585-1614

54. Wolff V, Schlagowski Al, Rouyer O, Charles AL, Singh F, et al. (2015) Tetrahydrocannabinol induces brain mitochondrial respiratory chain dysfunction and increases oxidative stress: a potential mechanism involved in cannabisrelated stroke. BioMed research international.

55. Volkow ND, Baler RD, Compton WM, Weiss SR (2014) Adverse health effects of marijuana use. N Engl J Med 370: 2219-2227.

56. Stefano GB, Kream RM (2015c) Personalized- and One- Medicine: Bioinformatics Foundation in Health and its Economic Feasibility. Medical Science Monitor 21: 201-204.

57. Aliev G, Obrenovich ME, Tabrez S, Jabir NR, Reddy VP, et al. (2013) Link between cancer and Alzheimer disease via oxidative stress induced by nitric oxide-dependent mitochondrial DNA overproliferation and deletion. Oxidative medicine and cellular longevity.

58. Aliev G, Priyadarshini M, Reddy VP, Grieg NH, Kaminsky Y, et al. (2014) Oxidative stress mediated mitochondrial and vascular lesions as markers in the pathogenesis of Alzheimer disease. Curr Med Chem 21: 2208-2217.

59. Westermann B (2009) Nitric oxide links mitochondrial fission to Alzheimer's disease. Sci Signal 2: pe29.

60. Nakamura T, Cho DH, Lipton SA (2012) Redox regulation of protein misfolding, mitochondrial dysfunction, synaptic damage, and cell death in neurodegenerative diseases. Exp Neurol 238: 12-21.

61. Khan A, Vaibhav K, Javed H, Khan MM, Tabassum R, et al. (2012) Attenuation of $A \hat{l}^{2}$-induced neurotoxicity by thymoquinone via inhibition of mitochondrial dysfunction and oxidative stress. Mol Cell Biochem 369: 55-65.

62. Massaad CA, Amin SK, Hu L, Mei Y, Klann E, et al. (2010) Mitochondrial superoxide contributes to blood flow and axonal transport deficits in the Tg2576 mouse model of Alzheimer's disease. PLoS One 5: e10561.

63. Jayanthi S, Buie S, Moore S, Herning RI, Better W, et al. (2010) Heavy marijuana users show increased serum apolipoprotein C-III levels: evidence from proteomic analyses. Mol Psychiatry 15: 101-112.
64. Sarafian TA, Habib N, Oldham M, Seeram N, Lee RP, et al. (2006) Inhaled marijuana smoke disrupts mitochondrial energetics in pulmonary epithelial cells in vivo. American journal of physiology. Lung cellular and molecular physiology 290: L1202-1209.

65. Sarafian TA, Habib N, Oldham M, Seeram N, Lee RP, et al. (2003) Delta 9-tetrahydrocannabinol disrupts mitochondrial function and cell energetics. American journal of physiology Lung cellular and molecular physiology 284 L298-L306.

66. Sarafian TA, Habib N, Oldham M, Seeram N, Lee RP, et al. (2008) Clarifying CB2 receptor-dependent and independent effects of THC on human lung epithelial cells. Toxicol appl pharmacol 231: 282-290.

67. Athanasiou A, Clarke AB, Turner AE, Kumaran NM, Vakilpour S, et al. (2007) Cannabinoid receptor agonists are mitochondrial inhibitors: a unified hypothesis of how cannabinoids modulate mitochondrial function and induce cell death Biochemical and biophysical research communications 364: 131-137.

68. Catanzaro G, Rapino C, Oddi S, Maccarrone M (2009) Anandamide increases swelling and reduces calcium sensitivity of mitochondria. Biochem Biophys Res Commun 388: 439-442.

69. Capettini LS, Savergnini SQ, da Silva RF, Stergiopulos N, Santos RA, et al (2012) Update on the role of cannabinoid receptors after ischemic stroke. Mediators Inflamm 2012: 824093

70. Silva GB, Atchison DK, Juncos LI, García NH (2013) Anandamide inhibits transport-related oxygen consumption in the loop of Henle by activating CB receptors. American journal of physiology. Renal physiology 304: F376-381

71. Chiu P, Karler R, Craven C, Olsen DM, Turkanis SA (1975) The influence of delta9-tetrahydrocannabinol, cannabinol and cannabidiol on tissue oxygen consumption. Research communications in chemical pathology and pharmacology 12: 267-286.

72. Agilli M, Aydin FN, Kurt YG, Cayci T3 (2015) Evaluation of leptin with atherosclerosis in rheumatoid arthritis. J Rheumatol 42: 727.

73. Bartels CM, Saucier JM, Thorpe CT, Kind AJ, Pandhi N, et al. (2012) Monitoring diabetes in patients with and without rheumatoid arthritis: a Medicare study. Arthritis Res Ther 14: R166.

74. Bartels CM, Wong JC, Johnson SL, Thorpe CT, Barney NP, et al. (2015) Rheumatoid arthritis and the prevalence of diabetic retinopathy. Rheumatology (Oxford) .

75. Chen DY, Chen YM, et al. (2015) Significant effects of biologic therapy on lipid profiles and insulin resistance in patients with rheumatoid arthritis. Arthritis Res Ther 17: 52

76. Clarson L, Hider SL, Belcher J, Heneghan C, Roddy E, et al. (2015) Response to: 'Risk of vascular disease with gout: overadjustment of the statistical analyses?' by van Durme et al. Ann Rheum Dis 74: e10.

77. de la Torre JC, Stefano GB (2000) Evidence that Alzheimer's disease is a microvascular disorder: the role of constitutive nitric oxide. Brain Res Brain Res Rev 34: 119-136.

78. Kuo D, Crowson CS, Gabriel SE, Matteson EL (2014) Hyperuricemia and incident cardiovascular disease and noncardiac vascular events in patients with rheumatoid arthritis. International journal of rheumatology.

79. Makol A, Crowson CS, Wetter DA, Sokumbi O, Matteson EL, et al. (2014) Vasculitis associated with rheumatoid arthritis: a case-control study. Rheumatology (Oxford) 53: 890-899.

80. Mankad R1 (2015) Atherosclerotic vascular disease in the autoimmune rheumatologic patient. Curr Atheroscler Rep 17: 497

81. Nordin A, Jensen-Urstad K, Björnådal L, Pettersson S, Larsson A, et al. (2013) Ischemic arterial events and atherosclerosis in patients with systemic sclerosis: a population-based case-control study. Arthritis research \& therapy 15: R87.

82. Ptacek R, Kuzelova H, Stefano GB, Raboch J, Kream RM, et al. (2014) ADHD and growth: questions still unanswered. Neuro Endocrinol Lett 35: 1-6.

83. Ramirez GA, Rovere-Querini P, Sabbadini MG, et al. (2015) Parietal and intravascular innate mechanisms of vascular inflammation. Arthritis Res Ther 17: 16.

84. Sheehan MH, Kream RM, Stefano GB (2010) Biological indications of a nove "short" $\mu$ opiate receptor in domestic chicken. Arch Med Sci 6: 478-482.

85. Tomasson G, Peloquin C, Mohammad A, Love TJ, Zhang Y, et al. (2014) Risk for cardiovascular disease early and late after a diagnosis of giant-cell arteritis: 
Citation: Stefano GB, Quinn E, Kream RM (2015) Endocannabinoid Stimulated Release of Nitric Oxide and its Mitochondrial Influence Triggering Vascular Pathology. Pharm Anal Acta 6: 378. doi:10.4172/21532435.1000378

Page 6 of 6

a cohort study. Ann Intern Med 160: 73-80.

86. Wang F, Guo X, Shen X, Kream RM, Mantione KJ, et al. (2014) Vascular dysfunction associated with type 2 diabetes and Alzheimer's disease: a potential etiological linkage. Med Sci Monit Basic Res 20: 118-129.

87. Kream RM, Kuzelova H, Kralickova M, Ptacek R, Stefano GB (2012) Comorbidity and self medication in schizophrenia: involvement of endogenous morphine signaling mechanisms. Curr Drug Targets 13: 1454-1457.

88. Stefano GB, Goumon Y, Bilfinger TV, Welters I, Cadet P (2000a) Basal nitric oxide limits immune, nervous and cardiovascular excitation: Human endothelia express a mu opiate receptor. Prog Neurobiol 60: 513-530

89. Stefano, G.B., and R.M. Kream. 2015b. Nitric Oxide Regulation of Mitochondrial Processes: Commonality in Medical Disorders. Annals of Transplantation. in press

90. de la Torre JC, Mussivand T (1993) Can disturbed brain microcirculation cause Alzheimer's disease? Neurol Res 15: 146-153.
91. Stefano G.B, RM Kream. 2015b. Nitric Oxide Regulation of Mitochondrial Processes: Commonality in Medical Disorders. Annals of Transplantation. in press.

92. Stefano GB, Mantione KJ, Casares FM, Kream RM (2015) Anaerobically functioning mitochondria: Evolutionary perspective on modulation of energy metabolism in Mytilus edulis. Invertebrate Survival Journal. 12: 22-28.

93. Esch T, Stefano G (2002) Proinflammation: a common denominator or initiator of different pathophysiological disease processes. Med Sci Monit 8: HY1-9.

94. Stefano GB, Kream R (2015a) Psychiatric Disorders Involving Mitochondrial Processes. Psychology Observer. 1: 1-6.

95. Bilfinger TV, Fricchione GL, Stefano GB (1993) Neuroimmune implications of cardiopulmonary bypass. Adv. Neuroimmunol. 3: 277-288.

96. Bilfinger TV (1999) Role of morphine in blood pressure modulation: influence of nitric oxide. Acta Pharmacol Sinica. 20: 458-459. 